ISSN: 1641-4713; e-ISSN: 2081-1160

DOI: https://doi.org/10.36551/2081-1160.2020.26.135-160

\title{
Saboreando o néctar: bem viver e ontologia na prática do Movimento Hare Krishna no sul do Brasil ${ }^{1}$
}

\author{
Savoring Nectar: good living and ontology in the practice of the Hare \\ Krishna Movement in southern Brazil
}

\author{
Victor Hugo Oliveira Silva \\ Universidade Federal do Paraná, Brasil \\ ORCID iD: https://orcid.org/0000-0002-4417-4585 \\ E-mail: oliveirasilvavictorhugo@gmail.com \\ Carolina Simões Pacheco \\ Universidade Federal do Paraná, Brasil \\ ORCID iD: https://orcid.org/0000-0003-3722-7914 \\ E-mail: carolsp9@gmail.com
}

Recepción: 28.02.2020

Aprobación: 10.04.2020

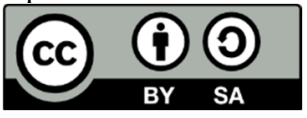

Resumo: Neste artigo indagamos o possível caráter político que reside no engajamento em práticas religiosas. Para isso buscamos compreender como o movimento Hare Krishna constitui uma ontologia própria que orienta a ação dos adeptos. O estudo foi realizado a partir de uma vivência de campo na rede de templos da 'ISKCON Sul Yatra' e da seleção de trechos de textos publicados na revista 'Carta de Sankirtana', produzida por integrantes do movimento. Nos inspiramos, ao analisar tais dados qualitativos, na concepção de ontologias políticas e na noção de 'bem viver', relacionando-as com a concepção nativa de 'néctar'. Constatamos que são as principais atividades do movimento, a distribuição de livros e de alimentos, que implicam em engajamento coletivo na busca deste 'néctar'. Identificamos, ainda, a característica juvenil como marcante do movimento Hare Krishna, pois a maioria de seus integrantes é constituída por jovens e o definimos, portanto, como coletivo juvenil. Concluímos, assim, que a ontologia do movimento Hare Krishna pode ser compre-

\footnotetext{
${ }^{1} \mathrm{O}$ presente trabalho foi realizado com apoio da Coordenação de Aperfeiçoamento de Pessoal de Nível Superior - Brasil (CAPES) - Código de Financiamento 001.
} 
endida como política, pois exprime em si uma concepção de devir e, simultaneamente, provoca engajamento em atividades coletivas, baseado em sentimentos que são descritos, eles mesmos, como fatores de adesão.

Palavras chave: Movimento Hare Krishna, Bem Viver, ontologias múltiplas; Sociologia da Juventude; emoções.

\begin{abstract}
In this article we investigate the possible political character that lies in engaging in religious practices. For this, we seek to understand how the Hare Krishna movement constitutes its own ontology that guides the action of its followers. The study was carried out from a field experience in the 'ISKCON Sul Yatra' network of temples and from the selection of excerpts from texts published in the magazine 'Carta de Sankirtana', produced by members of the movement. We are inspired, when analyzing such qualitative data, in the conception of political ontologies and in the notion of 'well living', relating it to the native conception of 'nectar'. We found that the main activities of the movement, the distribution of books and food, imply collective engagement in the search for this 'nectar'. We also identified the youth characteristic as a hallmark of the Hare Krishna movement, since most of its members are young people and we define it, therefore, as a youth collective. We conclude, therefore, that the ontology of the Hare Krishna movement can be understood as politics, as it expresses itself a conception of becoming and, simultaneously, causes engagement in collective activities, based on feelings that are themselves described as adherence factors.
\end{abstract}

Keywords: Hare Krishna movement, living well; multiple ontologies; sociology of youth; emotions.

INTRODUÇÃO

Este movimento de sankirtana é a principal bênção para toda a humanidade em geral porque espalha os raios da lua da bênção. É a vida de todo o conhecimento transcendental. Ele aumenta o oceano de êxtase transcendental, e nos capacita a saborear completamente o néctar pelo qual sempre ansiamos.

Caitanya Mahaprabhu, Siksastaka, verso 1

A partir de 2011, quando o monge Hara Kanta Das (uruguaio de 65 anos e membro do movimento desde 1980) assumiu a presidência do templo de Curitiba ${ }^{2}$, o movimento Hare Krishna veio crescendo no sul do Brasil, processo esse

\footnotetext{
${ }^{2}$ Fundada em 1623, essa cidade é atualmente a capital do Paraná, um dos três estados que compõe a região sul do Brasil. Tem uma população estimada de 1.948.626 habitantes, segundo o IBGE (2020). Seu nome de origem tupi-guarani e significa 'terra de muitos pinheirais', fazendo referência a grande quantidade de araucárias (auraucaria angustifolia) que havia anteriormente na região. Como diversas outras cidades brasileiras, tem em sua origem a miscigenação entre povos indígenas, africanos e europeus. Apesar disso, devido a influência das migrações alemãs, polonesas e italianas, a partir do final de século XIX, e também ao frio - característica dessa região de clima temperado é tida no imaginário de senso comum brasileiro como uma 'capital europeia', mesmo apresentando um terço de sua população autodeclarada preta e/ou parda, dados do IBGE. Segundo um estudo da UNESCO de 1999, sobre os jovens da capital paranaense: "Em Curitiba convivem várias Curitibas. Por mais que essa frase seja senso comum, é a melhor síntese que encontramos para expressar as representações encontradas. Os jovens visualizam mais fortemente a cidade do lazer - espaço do
} 
que culminou na constituição de uma rede integrada de projetos chamada por seus integrantes de ISKCON Sul Yatra ${ }^{3}$, formada por quatro templos (em Curitiba, Itajaí, Florianópolis e Porto Alegre) e dois centros culturais (Camboriú e Blumenau).

Ao voltarmos o olhar para as práticas que impulsionam o crescimento e motivam o engajamento vemos que, através do serviço das pessoas envolvidas nessas comunidades, segundo um levantamento do próprio movimento, foram distribuídos em torno de 378.240 livros de Bhaktivedanta Swami Prabhupada, mestre bengali fundador do movimento, desde 2011. Além disso, são distribuídos semanalmente e de forma gratuita em torno de 300 pratos de refeições vegetarianas, consideradas espiritualizadas por terem sido primeiramente ofertadas a Krishna.

Devido à realização dessas atividades e ao treinamento espiritual oferecido, atualmente cerca de 50 pessoas moram nessas diferentes comunidades urbanas - a maioria jovens entre 18 e 30 anos. Essa expansão, inusitada, tendo em vista a situação do movimento em outras regiões do Brasil - que vem buscando formas mais discretas de inserção na sociedade - está diretamente ligada às duas práticas principais realizadas por seus integrantes: a distribuição de livros (sankirtana $)^{4}$ e de alimentos (prasadam $)^{5}$. Essas práticas são baseadas em princípios

lúdico, que oferece entretenimento e áreas verdes - que a cidade fria, que afasta e oprime os não curitibanos. É a cidade que amam, embora não a isente de críticas. Visualizam predominantemente seus aspectos positivos, como o espaço de sua sociabilidade, mas com problemas sociais (...). De um lado a cidade imagem, filha do planejamento urbano e das intervenções no espaço físico realizadas pela sua elite política, visibilizada como uma estratégia bem sucedida de marketing e vendida como um produto da moda; de outro a cidade da espoliação urbana, do esgoto a céu aberto, da falta de saneamento básico, da omissão do Estado" (Sallas et al., 1999, pp. 85-86).

${ }^{3}$ A ISKCON (acrônimo para International Society for Krishna Consciousness) se encontra presente em todo Brasil, no entanto, os templos que elenquei como sendo integrantes da rede têm entre si uma certa coesão interna por serem liderados e administrados por um mesmo devoto sênior. Isso não significa que esses templos e seus integrantes não mantenham relações com templos e devotos de outras partes do Brasil, mas que, mesmo entre os devotos brasileiros, existe um certo consenso a respeito da importância do "humor de sankirtana dos devotos do sul".

4 Palavra que em sânscrito significa "canto congregacional dos santos nomes". Ele faz referência ao meio principal através do qual Sri Caitanya difundiu seu movimento devocional, as procissões públicas de canto do maha mantra Hare Krishna pelas ruas (Carvalho, 2018, p. 52). Posteriormente, mediante uma extensão metafórica, esse termo passou a ser designado para se referir a prática de distribuição de livros nas ruas, a qual - após o mestre de Prabhupada inserir o uso de gráficas na prédica do movimento no século XIX - passou a ser considerada com uma forma ainda mais abrangente de difundir a vibração do mantra, sendo os livros metaforicamente comparados a grandes tambores (bhrat Mrdanga), instrumento usado no canto coletivo.

5 Termo em sânscrito que pode ser traduzido como "graça" ou "misericórdia" e é, no dia a dia dos devotos, usado para se referir ao alimento que foi primeiramente oferecido a Krishna, através das formas adoráveis (deidades) presentes no altar. Os membros do movimento consideram que, assim como o maha-mantra, o alimento oferecido se torne tão bom e transcendental quanto o próprio Krishna, nesse sentido, aqueles que dele se alimentam obtém avanço espiritual, mesmo que não conheçam nada a respeito da filosofia. 
comunitários, que têm a humildade, a renúncia e o serviço devocional como elementos centrais de seu 'humor' - categoria nativa utilizada para se referir ao estado de consciência em que se realiza uma determinada atividade.

O movimento Hare Krishna foi oficialmente fundado no Ocidente, em Nova York, no ano de 1966, pelo renunciante bengali chamado Abhay Caranaravinda Bhaktivedanta Swami Prabhupada. Posteriormente, foi trazido para o Brasil em diferentes ondas, a partir de 1973 (Carvalho, 2018). Esse movimento é considerado uma manifestação contemporânea de uma das linhas do chamado hinduísmo tradicional (Valera, 2015, p. 14) conhecida como vaishnavismo gaudiya, inaugurado por Sri Caitanya Mahaprabhu por volta de 1530. O vaishnavismo é um termo utilizado pelos indólogos modernos para fazer referência a uma manifestação histórica do sistema filosófico-religioso dos adoradores de Vishnu, mais conhecidos como vaishnavas (Valera, 2015, p. 15). O termo inclui também aqueles que adoram Krishna e Narayna, tidos como diferentes formas de uma divindade pessoal e suprema. O termo 'gaudiya', utilizado pelo vashnavismo moderno e proeminente trazido por Swami Prabhupada, indica uma região no norte da Índia chamada 'terra de Gauda', onde esse tipo de vaishnavismo se originou. Vemos assim que o crescimento do movimento Hare Krishna em cidades brasileiras é resultado de diversas mediações entre Oriente e Ocidente, Calcutá e Nova York, entre o transcendental e o material.

Esse crescimento implicou, ademais, num engajamento constante, que faz da ação missionária uma espécie de militância, a partir do referencial da ação coletiva, que estabelece repertórios de ação e performances para efetivá-los (Tilly, 2006). Esse engajamento acontece em prol daquilo que os integrantes do movimento entendem como sendo uma "revolução espiritual", em que as ações e associações do movimento produzem transformações nas respectivas cidades onde ocorrem. Isso acontece devido à distribuição sistemática de alimentos gratuitos, à realização periódica de festivais devocionais e à promoção de estudos diários sobre as escrituras vaishnavas, especialmente a Bhagavad-Gita ${ }^{6}$. Ou seja, a atuação

\footnotetext{
${ }^{6}$ É uma das principais escrituras védicas para o vaishnavismo, juntamente com o Bhagavata Purana e o Caitayia Caritamrta. É lida e debatida diariamente nos estudos vespertinos realizados diariamente nos templos, além de ser distribuído nas ruas buscando a propagação e manutenção do movimento. Devido a sua importância é chamada por alguns de 'Bíblia' hindu, apesar de ser mais antiga. A Bhagavad Gita é uma parte do Mahabharata, uma epopéia que narra a história do mundo antigo. Se constitui basicamente de um diálogo entre Krishna e seu amigo Arjuna, momentos antes da grande batalha na qual culmina a narrativa. Nessa conversa se transmite a ciência da autorrealização em suas múltiplas formas, culminando na apresentação do serviço devocional como ápice do processo de yoga. Assim como ocorre com outros textos da literatura védica, cuja transmissão era originalmente feita através da oralidade, a datação dessa escritura é um tema polêmico. Para os
} 
do movimento Hare Krishna não está dissociada do meio no qual seus integrantes vivem e, assim como são mobilizados a partir de um questionamento deste meio, incidem sobre ele de maneiras bastante específicas, como veremos adiante.

Tendo em vista essa conjuntura, este artigo pretende, ao considerar o ponto de vista nativo sobre suas práticas, indagar o caráter potencialmente político que reside em se engajar na produção coletiva de uma ontologia, através da busca pela produção daquilo que ela apresenta como sua noção particular de bem viver, tal como elaborado por Acosta (2016). Para tal intenção, exploraremos a concepção de política apresenta por Mol (1999), para quem, esta pode ser entendida a partir de um sentido ontológico, como sendo ligada à possibilidade de definição das condições de produção da realidade e não somente como uma ação circunscrita ao que institucionalmente se entende como política. A realidade é entendida, portanto, não como pré-existente, mas modelável a partir de práticas em redes de associações que acionam diferentes agências e seres. Nesse sentido, o termo política serve para enfatizar essa produção ativa da realidade, entendida como um processo de modelagem com um caráter simultaneamente aberto e contestável (Mol, 1999).

Complementando essa concepção, o termo ontologia será aqui utilizado como forma de se referir a multiplicidade de mundos possíveis, algo que o conceito de cultura teria perdido a capacidade de expressar, especialmente quando atua como uma forma de projetar nos outros, uma maneira particularmente ocidental de pensar a si mesmo e a diferença, fundamentada em grandes binômios como nós/eles, dentro/fora, natureza/cultura. Nesse sentido, o uso de termo ontologia envolve uma atenção ao modo pelo qual a multiplicidade de formas de existência organiza práticas concretas, buscando cultivar um olhar atento ao modo como pessoas e coisas podem se alterar por elas mesmas, podem existir de diversos modos (Viveiros de Castro, 2003).

Para tanto, dividiremos este artigo da seguinte maneira. Na primeira parte, apresentamos uma consideração acerca dos métodos utilizados para a realização da pesquisa aqui relatada, buscando um aprofundamento no que tange o uso da etnografia como um recurso antropológico. Num segundo momento, a partir de elementos da atuação do movimento Hare Krishna, buscaremos apresentar os diferentes eixos de ações em torno dos quais se produz o bem viver tal como localmente compreendido. Na terceira parte, buscando um diálogo com as

devotos ela seria um relato fidedigno desse diálogo histórico e factual que teria ocorrido há cinco mil anos; entre os acadêmicos existe um consenso de que essa obra teria sido vertida para versão escrita por volta dos séculos V e II AEC (Theodor, 2015). 
ideias de Mol (1999), apresentaremos a análise efetiva da questão proposta relacionando o néctar como bem viver para pensar como as atividades tomadas como base para reflexão podem indicar um caminho para uma compreensão mais ampla da política.

\section{A PARTICIPAÇÃO OBSERVANTE: CONSTRUINDO UM PONTO DE VISTA METODOLÓGICO}

Para a realização das reflexões que compõem este artigo utilizamos dois materiais de referência. O primeiro é uma pesquisa documental, que teve como corpus de análise uma revista mensal produzida pelos membros do movimento chamada 'Carta de Sankirtana', que consideramos representativa, à medida em que se constitui de um conjunto de publicações periódicas que exprimem a visão do movimento acerca de si e de suas atividades. Essa revista, cujo acervo está disponível online, serve para divulgação dos resultados mensais da distribuição dos livros do fundador do movimento, além de apresentar entrevistas e editoriais que buscam estimular essa prática.

Atualmente, a editora chefe da revista é uma das residentes do templo de Curitiba, chamada Vaishnavi Vrnda Devi Dasi. Além disso, ao longo do ano de 2018, a maior parte dos editoriais e entrevistas foram feitos por e com membros da ISKCON Sul Yatra, setor do movimento Hare Krishna no Brasil que aqui tomamos como objeto de nossa reflexão. Dessa forma, consideramos que os textos e entrevistas apresentados em tal revista são materiais importantes pois exprimem a forma que os próprios membros do movimento conferem sentido ao seu engajamento - processo esse que tem na atividade missionária de distribuição de livros sua expressão central. Tomar tais relatos como fonte de pesquisa é, portanto, uma maneira de acessar elementos a partir dos quais esses agentes justificam seu engajamento, buscando neles observar quais os pressupostos ontológicos em questão, ou seja, o que se faz, por que e qual mundo se produz a partir dessa ação?

O segundo material que embasa essa pesquisa é constituído pelas reflexões produzidas pelo autor a partir da vivência de campo na rede de templos da ISKCON Sul Yatra. Essa relação com o movimento que se desenrola como inserção pessoal desde o ano de 2009. Tais indagações vem tomando forma como material etnográfico a partir do ano de 2018, quando o autor ingressou no doutorado em Sociologia na Universidade Federal do Paraná, tendo os festivais devocionais realizados pelo movimento Hare Krishna como tema de pesquisa. Como é de se esperar numa pesquisa ainda em andamento, as próprias questões têm se 
transformado ao longo desse encontro. No entanto, nesse texto, buscando elaborar a discussão proposta, trabalharemos com algumas premissas epistêmicas fornecidas pela etnomedotologia, para recortar algumas anotações e reflexões feitas em campo.

Essa corrente do pensamento sociológico se desenvolveu a partir dos anos 60, pela obra de autores como Garfinkel (2006). Valorizando metodologias qualitativas como a etnografia e opondo-se a paradigmas positivistas, nos quais aos indivíduos cabe apenas a reprodução de papéis pré-definidos dentro de uma estrutura social dada, esse pensador propôs tomar os fatos sociais como sendo construídos nas interações por meio de processos de linguagem e negociação contínuos e situados. Assim, os agentes envolvidos são tidos como capazes de articular procedimentos próprios para definir circunstâncias e significados perante as situações.

Inspirando-se nessas premissas a pesquisa empírica deve buscar, na medida do possível, se abster de concepções a priori, tendo como foco os métodos que os membros de um coletivo utilizam para dar sentido e, ao mesmo tempo, realizar suas atividades diárias. Ao se encontrar em campo o interesse é observar simultaneamente como os membros de um grupo agem a partir dos pontos de vista que possuem e, ao mesmo tempo, se atentar aos métodos que fazem com que essas mesmas atividades sejam racionais e relatáveis a todos os fins práticos, ou seja, descritíveis enquanto organização ordinária das atividades diárias.

Partindo disso, pude tomar as interações nas principais práticas do movimento como formas palpáveis de se obter acesso a experimentos empíricos do pensamento, que se encontram em questão nas formas pelas quais os indivíduos conferem um sentido prático às suas atividades cotidianas. Assim, desenhamos um caminho teórico para tratar sociologicamente acerca de temas que são fundamentais para as pessoas implicadas no movimento Hare Krishna, como a produção da prasadam (alimento espiritualizado) e a potência espiritual dos livros como ferramenta missionária, bem como o atendimento pessoal e devocional às Deidades em torno do qual gira o cotidiano dos templos. Nessa perspectiva processual vemos que não existem grupos dados, pré-determinados, mas apenas a formações de grupos, princípios interacionais que orientam a ação social em situações circunscritas num movimento situado.

A metodologia utilizada é assim de cunho qualitativo, sendo que parte das ideias que são apresentadas neste artigo resultam de 'revelações compartilhadas', possibilitadas pela vivência de práticas específicas no movimento enquanto alguém que participou das atividades em questão.Nesse processo de pesquisa, o que se pretendia como um distanciamento, implícito na proposta clássica 
malinoswakiana de observação participante, se transformou, ou, melhor dizendo, foi ressignificado, na relação com os interlocutores. Devido a isso, essa pesquisa pode ser melhor entendida como um processo pelo qual o autor foi 'afetado', nos termos de Favrett-Saada (Velho, 1998). Para esta antropóloga, que realizou sua pesquisa de campo sobre a feitiçaria no Bocage Francês, "deixar-se afetar pelo nativo pressupõe que 'ele/ela' tenha algo a nos ensinar. Não apenas sobre ele mesmo, mas sobre nós" (Velho, 1998, p. 12). Em sua pesquisa, esta antropóloga percebeu o quanto seus interlocutores resistiam aos pressupostos que visavam uma divisão radical entre pesquisador e pesquisado, de forma que ela se via envolvida pelas suas tramas, sendo parte integrante das mesmas:

Assim, alguns pensaram que eu era uma desenfeitiçadora e dirigiram-se até a mim para solicitar o ofício; outros pensaram que eu estava enfeitiçada e conversaram comigo para me ajudar a sair desse estado. Com exceção dos notáveis (que falavam voluntariamente de feitiçaria, mas para desqualificá-la), ninguém jamais teve a ideia de falar disso comigo simplesmente por eu ser etnógrafa. Eu mesma não sabia bem se ainda era etnógrafa (Favret-Saada, 1977, p. 157)

De modo parecido, mas com colorações específicas, os relacionamentos que o autor veio a estabelecer com seus interlocutores não se deram porque havia uma pesquisa em desenvolvimento. Ele foi compreendido pelos interlocutores como alguém envolvido no mesmo processo de purificação da consciência na prática do serviço devocional, alguém que integra, apesar da intermitência, a mesma trama do serviço e, às vezes, é visto como um 'jornalista transcendental', fazendo entrevistas e anotações para a produção de uma pesquisa em andamento.

Assim a inscrição no campo não aconteceu como a de um estudioso que se vê imerso em um sistema de referência diverso, em que o elemento primário e definidor da relação é a pesquisa e, ao mesmo tempo, se afastou dos casos daqueles que se voltam para a pesquisa devido ao interesse religioso, tentando sobrepor diferentes regimes de verdade. Buscando seguir o conselho de Segato (1992), em importante texto sobre esta questão, venho buscando não "exorcizar ou resolver a diferença", almejando traduzir essas experiências ao conhecimento das Ciências Humanas, e mais especificamente, da Antropologia e da Sociologia. A partir desse lugar, entre pesquisador e praticante de bhakti-yoga e em meio às inconstâncias da vida material, é que pretendo elaborar a presente reflexão. 


\section{O NÉCTAR COMO BEM VIVER PARA OS HARE KRISHNA}

Buscando observar as ações empreendidas pelos membros do movimento como uma ação coletiva (Tilly, 2006), almejamos perceber o modo pelo qual as atividades cotidianas são ritualizadas, para fazer da vida dos praticantes um tipo de oferenda ou sacrifício a Krishna (a suprema personalidade de Deus). Dessa forma, a dinâmica dessas atividades cotidianas das comunidades observadas pode ser concebida como sendo fundamentada em quatro eixos: o cantar dos santos nomes (através do maha mantra Hare Krishna Hare Krisha Krishna Krishna Hare Hare Hare Rama Hare Rama Rama Rama Hare Hare ${ }^{7}$ ), as atividades ritualísticas de adoração diária às Deidades presentes no altar; a distribuição dos alimentos espiritualizados e a venda dos livros do fundador do movimento.

Os dois primeiros eixos produzem a dinâmica de interação interna das comunidades, mediante a busca por atender com preparações, cânticos, guirlandas, roupas e banhos as formas divinas presentes no altar, de acordo ao padrão estipulado pelo mestre espiritual e pelas escrituras. Já os outros dois eixos estão ligados às formas pelas quais as dinâmicas interativas das atividades acabam por estender essa rede de associações, partindo da comunidade em direção à rua e à cidade. Ou seja, a distribuição dos alimentos espiritualizados e a venda dos livros do fundador do movimento são orientadas para 'os outros', aqueles que não são adeptos do movimento. A interação entre devotos e os 'outros' se dá através da figura do distribuidor de livros, que aborda as pessoas para falar de Krishna, solicitar doações aos templos e convidar para os festivais, e também pela distribuição da prasadam.

A interrelação entre os diferentes eixos, bem como a centralidade da distribuição de livros nesse processo, foi descrita por Rasarnava Gouranga, um jovem de 23 anos, em uma entrevista concedia à Carta de Sankirtana, em que ele pontuou que:

Srila Prabhupada nos ensinou que "os livros são a base"; são eles, portanto, que sustentam todo o nosso Movimento. Sustentam tanto financeiramente, como uma fonte de renda para os templos, como espiritualmente, dando uma boa consciência para os devotos. Prabhupada nos ensina que "pregação é a essência" e que a melhor pregação é a distribuição de seus livros. Quando se tem consciência de pregação, todas as diferentes atividades do templo são bem executadas, desde a limpeza, cozinha, pujari, aula etc. Pois os sankirtaneiros estão nas ruas convidando as pessoas a virem ao templo, e tudo deve estar bom para recebê-los. Em uma palestra de Chaitanya-chandra Prabhu (campeão mundial

\footnotetext{
${ }^{7}$ Hare é uma invocação ao aspecto feminino de Deus, Krishna significa aquele que atrai a todos e Rama, a fonte de todo prazer. Desse modo a tradução deste mantra, segundo Prabhupada, seria "Senhor e suas energias, por favor, façam-me um instrumento de seu amor" (Prabhupada, 1979).
} 
de sankirtana), foi dito por ele que o fruto maduro da árvore de bhakti só pode ser experimentado quando compartilhado. Portanto, a distribuição de livros, além de beneficiar muito as almas condicionadas, outorga um avanço espiritual imensurável aos sankirtaneiros. (Devi Dasi, 2019b, pp. 11-12)

Destacamos, ademais, que é na realização das atividades implicadas em tais eixos que o próprio processo de constituição - sempre provisório - do grupo acontece enquanto tal, bem como dos próprios membros em suas condições enquanto devotos. O sentimento de pertencimento ao movimento não é fixo e parte, como demonstramos, da realização permanente das atividades devocionais.

$\mathrm{O}$ objetivo fundamental desses quatro eixos de atividades associadas é descrito, ainda, como a promoção de uma purificação da consciência, mediante a associação concreta entre as almas individuais e Krishna, situação essa que se estabelece pelo canto, pelo alimento oferecido (prasadam), pelos livros e pelas Deidades. Esse processo de transmutação dos elementos da matéria em algo divino ocorre pelo contato desta com o som de mantras específicos, entoados conforme a ritualística observada. Esses sons são concebidos como sendo imbuídos de poder, tanto por aquilo que se considera como sendo a natureza transcendental dos mesmos, quanto pela fé do devoto que os entoa. Os livros que os 'sankirtaneiros' distribuem são então tidos, como podemos perceber no trecho abaixo, como imbuídos da mesma potência contida nos mantras:

Krishna diz na Bhagavad-gita (4.36): "Mesmo que o mais baixo de todos os pecadores pode facilmente cruzar este oceano de misérias por simplesmente situar-se no barco do conhecimento transcendental!" Como entrar neste barco? O devoto puro de Krishna tem os bilhetes de passagem! Assim, a transcendental função do sankirtaneiro é não apenas entregar conhecimento filosófico, como, também, a transcendental associação de um devoto puro de Krishna (Sua Divina Graça A.C. Bhaktivedanta Swami Prabhupada)! Assim, o sankirtaneiro entrega o pacote completo à alma condicionada: o conhecimento e o professor. E a associação com um devoto puro é muito mística: lava-mātra sādhu-sange sarva-siddhi haya: mesmo por um instante de associação, alguém pode obter todo o sucesso! Por isso, Srila Prabhupada diz que ler apenas uma página de seu livro ocasiona uma revolução no leitor! O que concluímos a partir disso tudo é: a ocupação de um sankirtaneiro é absoluta e completamente gloriosa e prazerosa. (Devi Dasi, 2019c, pp. 2-4).

A partir do ponto de vista dos devotos Hare Krishna percebe-se que é através dos esforços implicados na realização das atividades do serviço devocional e missionário, que se torna possível integrar o jogo cósmico (lila). Esse, por sua vez, é caracterizado como a vinda da divindade que é tida por seus seguidores como o último avatar da personalidade de Deus a ter se manifestado na Terra, chamado Sri Caitanya. 
A palavra lila, no norte da Índia, significa 'jogo' e, assim, nomeia jogos e dramas. Mas lila é também usada para descrever um dos grandes ciclos festivos religiosos, o Ram Lila, no qual o épico Ramayana é encenado. Neste contexto, lila não significa nenhum jogo 'comum' ou teatro 'comum', mas comunica o fato de que os deuses e o divino estão se tornando animados e manifestos nesse mundo e, portanto, designa uma experiência intensificada do divino, caracterizada por um uso magnificado de muitos meios de comunicação e uma intensa e excitante participação da massa. (Tambiah, 1985, p. 137)

Nesse sentido poderíamos considerar que a performance do canto congregacional, da distribuição dos livros e da prasadam como um desses jogos cósmicos, através do qual o humor de Caitanya e sua presença divina se faz concretamente presente. Essa reflexão pode ser vislumbrada no trecho de um editorial escrito por Phalguna Nimai Das, de 30 anos, residente do templo de Curitiba e um dos distribuidores de livros mais experiente da comunidade:

Em Satya-yuga, o processo para despertar nossa consciência de Krishna era o sistema óctuplo de yoga, em um local isolado, seguindo regras e regulações e meditando em Vishnu-murti, a Superalma dentro do coração. Então, em Kali-yuga, isso não é possível. Nossa natureza psicológica e as condições de vida no planeta não permitem sucesso nesse sistema. Em Kali-yuga, Krishna veio como um devoto. E qual é a ocupação de um devoto? Um devoto glorifica a Krishna. Krishna é sobre excelente em todas as Suas atividades, e como devoto, Ele salva o mundo inteiro através da pregação da mensagem bhagavata. O processo para Kali-yuga é participar do Movimento de Sankirtana, espalhando por todo o mundo a mensagem transcendental do Srimad-Bhagavatam. E qual é o objetivo de espalhar essa mensagem? Causar uma revolução na vida ímpia das pessoas materialistas. Então, agora a meditação solitária não é efetiva. Um transcendentalista em Kali-yuga entra para a família do Senhor Caitanya. Nossa meditação é o canto congregacional dos santos nomes e a pregação. A Carta de Sankirtana é um veículo muito bom para aquecer nossos corações gelados com associação dos "bebedores e distribuidores do néctar da consciência de Krishna!" Que possamos nos contagiar com o entusiasmo dos soldados da linha de frente do exército do Senhor Caitanya e assim nos tornarmos pregadores e realizar nossos outros serviços com mais vigor e entusiasmo. Que sempre possamos ver e compartilhar nossas experiências aqui para incrementar nossa vida espiritual. (Devi Dasi, 2019a, p. 3)

As atividades dos quatro eixos do serviço estabelecem, como vimos, o caráter pragmático do jogo cósmico, em que o ato de participar da situação com consciência é o que produz o 'néctar', como uma 'experiência ontológica'. Ou seja, quando se desfruta, quando verdadeiramente se sente prazer na realização de tais atividades, se considera que o devoto tenha entrado em contato com a natureza eterna de sua alma, definida ontologicamente pelas escrituras vaishnavas como sendo uma parte fragmentária de Deus (Krishna), simultaneamente igual e ao mesmo tempo diferente dele. Nesse sentido, o serviço devocional (bhaktiyoga) é apontado como o caminho prático para que a pessoa possa ser novamente situada naquela que, do ponto de vista dos devotos, é a natureza eterna da alma. 
Destacar o 'néctar' como uma categoria do sistema de orientação ${ }^{8}$ que fundamenta a ontologia do movimento Hare Krishna foi possível mediante o que poderíamos chamar de experiência de mutualidade. Essa expressão faz referência à ideia de que certas compreensões sobre o modo de vida de um determinado coletivo não podem se dar através da distância, que por vezes os pesquisadores constroem para justificar suas análises. Nesse sentido, é importante ressaltar que a experiência de campo não implica apenas em uma vivência pessoal (subjetiva), mas sim em uma vivência prolongada de intersubjetividade, que se desenvolve por meio de revelações partilhadas, em que as próprias categorias com que compreendemos a realidade em estudo são reformuladas.

É nesse sentido de revelação compartilhada que a noção de 'néctar' se destacou como fundamento da tessitura de relações entre a produção coletiva do bem viver e suas implicações políticas. Inicialmente, o uso frequente da palavra 'néctar' no cotidiano devocional era percebido como algo trivial, uma espécie de termo ou gíria com a qual se habitua ao se inserir em um grupo novo de pessoas. Com o passar do tempo, porém, observando o fato de que ela era usada para adjetivar positivamente a experiência de se engajar nas principais frentes de ação do movimento, percebeu-se que a realização de tais atividades é que permite uma transição ontológica, dando à pessoa a possibilidade de estar participando na prática dos passatempos, ou lila, de Sri Krishna Caitanya. Essa participação nas atividades, por sua vez, tem como propósito cosmológico aflorar uma nova Era de Ouro $^{9}$, a partir do cantar maha-mantra e da distribuição de prasadam.

Devido a isso é que seria possível afirmar que o horizonte da realização dessas atividades pode ser compreendido como a produção da purificação, da consciência e dos relacionamentos. É nessa purificação, por sua vez, que se pode

\footnotetext{
${ }^{8}$ Tal como apontou José Edilson Teles (2016) "a noção de 'sistema' não deve ser entendida em sentido lato, como um modelo de fenômeno universal, um todo 'organizado'. Simplesmente busca descrever um conjunto de categorias construídas como um modo de orientação das práticas. Além disso, o termo "sistema de orientação" parece-me menos problemático que a noção de 'crença'. (...) Esse sistema orientação, constitui-se num conjunto de saberes e práticas valorizadas por meus interlocutores, de modo que não há razão para negligenciá-la ou subestimá-la". (Teles, 2016, p. 8)

9 "O sistema védico dos quatro yugas apresenta a duração das eras como 4, 3, 2 e 1 vezes um intervalo de 432.000 anos. Isso significa que a primeira era, Satya-yuga, dura 1.728 .000 de anos; a segunda, Treta-yuga, dura 1.296.000 milhões de anos; a terceira, Dvapara-yuga, dura 864.000 anos, ao passo que a atual Era de Ferro, Kali-yuga, dura 432.000 anos (...) O ciclo védico das Yugas descreve a civilização começando em um estado iluminado e avançado, seguido por um gradual declínio para o caos e a ignorância." (Swami, 2019, p. 257) Segundo os membros do movimento Hare Krishna estaríamos no ano 5000 da Era de Kali, a menos iluminada das eras, mas o cantar do maha mantra teria como potência neutralizar os efeitos negativos de tal conjuntura, criando possibilidades para vivência de uma 'era de ouro' mesmo nessa condição.
} 
desenvolver coletivamente o gosto necessário para aprender a saborear o 'néctar', ou seja, o 'bem viver', no sentido tal como compreendido por esses Hare Krishnas. Mas a que estamos nos referindo com a ideia de 'bem viver'? Como essa noção está associada a categoria nativa expressa pelo conceito de 'néctar'?

O conceito de 'bem viver' emerge como um modo de expressar o que há de político em se imaginar e praticar outros mundos possíveis. Segundo Acosta (2016), o 'bem viver', enquanto conceito, integra diferentes visões humanistas e antiutilitaristas, provenientes de diferentes partes do mundo. Apesar de ter surgido como uma referência às cosmologias ameríndias e seu ideal de um viver coletivo simultaneamente bom e belo, contido em expressões como o termo andino kíchwa sumak kawasaye e o termo guarani nhanderekó, ele está aberto a contribuições de outras ontologias e práticas, segundo Acosta (2016), que apontem para um viver coletivo responsável e consciente de sua interdependência e imbricação com a vida.

Nesse sentido, seguindo a compreensão proposta por eese autor, o 'bem viver' pode ser compreendido como um paradigma que abarca um espaço-temporal comum, no qual podem conviver distintas ontologias, na construção de uma interculturalidade que aponte alternativas de desenvolvimento social e humano.

Inspirado no uso que faz Gordon (2014) do conceito de 'bem viver', em seu trabalho com os indígenas xikrin-mebêngôkre (Kayapó), sugerimos que tal arcabouço pode ser incorporado ao contexto etnográfico da rede de templos Hare Krishna aqui analisada. Verificamos, assim, que é possível relacionar o conceito de 'bem viver' com o de 'néctar', de uso corrente no dia a dia devocional acima referido. Essa expressão, assim como 'bom' ou 'belo' (mejs) dos xikrin, carrega simultaneamente dimensões éticas e estéticas. Ela é usada para qualificar, de forma muito positiva, um alimento, uma leitura, uma aula ou um evento como expressões como: "nossa que "néctar' esse kirtan; "a prasada está um 'néctar"”; "que 'néctar' foi esse festival" (frases registradas pelo autor no trabalho de campo). Ao ser utilizada como conceito recorrente, o 'néctar' faz referência àquilo que é bom, bonito, desejável e transcendental, em oposição ao que é ilusório, material e temporário. Notamos, assim, uma relação desta significação com outros conceitos de 'bem viver' acima mencionados, de forma que podemos que os Hare Krishna fazem da produção do 'néctar', um modo particular de produção de si e do estabelecimento da diferença com os 'outros'.

Esse conceito nativo deriva, por sua vez, da palavra sânscrita amrta (aquilo que não morre). Assim como os conceitos de sumaka kawsay (de origem kíchwa) ou nhandereko (guarani), ele fez referência a uma relação particular entre 
ética e estética, ao perpassar o que é desejável e belo, coletivamente bem feito, sendo possível traduzi-lo como 'aquilo que é eterno'.

Na Bhagavad-Gita, principal escritura estudada no movimento Hare Krishna, encontramos uma menção a esse termo que nos aproxima da compreensão do modo pelo qual ele é utilizado no cotidiano dos devotos: "quando é capaz de transcender estes três modos associados com o corpo material, o ser encarnado pode liberar-se do nascimento, da morte, da velhice e dos sofrimentos que são inerentes a eles, e mesmo nesta vida pode gozar o 'néctar'" (Duarte, 1998, p. 169).

A noção de 'néctar', ou amrta, foi introduzida mais diretamente no vaishnavismo gaudiya por Rupa Goswami - erudito indiano do séc XVI - em seu tratado Bhakti Rasamrta Sindhu, no qual, ao transmitir os ensinamentos que ele havia recebido de Sri Caitanya, ele comparou o relacionamento amoroso com Deus (bhakti-rasa) a um nectáreo (amrta) oceano. Tal processo de inserção do termo foi registrado por Valera (2015), em sua tese de doutorado em Filosofia, sobre esse que é um dos principais livros do movimento Hare Krishna:

A ênfase em uma ontologia das emoções (bhakti-rasa) como uma exploração das implicações ontológicas dos princípios da estética indiana e sua noção de rasa garante a peculiaridade da tradição do Vaiṣnavismo Gauḍīya de Caitanya Mahāprabhu no contexto das demais escolas do Vedānta vaișṇava. Com efeito, há nele algo de absolutamente singular no que tange à natureza ontológica da Divindade: a eficácia do emocionalismo devocional que implica uma concepção de uma Divindade, enquanto expressão da doçura, intimidade e amor, que pode ser "degustada" em toda sua doçura (madhura). (Valera, 2015, p. 129)

A partir disso, compreende-se um pouco mais do porquê uns dos pratos mais valorizados em festivais sejam os muitos e variados tipos de doces que são ofertados às Deidades. Além disso, o conceito de 'néctar' faz referência a uma narrativa mítica, presente nas escrituras vaishnavas, na qual o néctar, ou sumo da imortalidade, é produzido pelos semideuses (devas) em cooperação com os demônios (asuras) durante a batedura do oceano de leite. Assim, ela faz menção a um processo que tem como resultado a manifestação de uma essência que é muito doce, sendo a doçura associada à imortalidade. Esse conceito reúne em si, como destacado, duas características centrais de serviço devocional (bhakti yoga) que anima as práticas, especialmente as culinárias, da rede em questão: faz referência a uma produção específica que ocorre mediante o cultivo de um processo, ritualmente orientado, e tem como resultado, por sua vez, a doçura.

Mediante essa reflexão poderíamos afirmar que o 'bem viver' buscado pelo movimento é produzido ritualmente por suas práticas principais. Essa busca acontece e se realiza, como demonstramos, no serviço devocional - fazendo 
e compartilhando o alimento e entrando em contato com o som transcendental, mediante o cantar dos santos nomes de Krishna e das escrituras vaishnavas.

Os festivais são celebrações dessa perspectiva por excelência, sendo uma espécie de esforço concentrado para produção do 'néctar'. Considera-se que, mediante tais situações, os praticantes possam iluminar uns aos outros falando sobre Krishna e, devido à purificação propiciada pelo serviço, desfrutar de um tipo de felicidade transcendental - estado esse geralmente qualificado através do uso dos adjetivos 'néctar' e 'nectáreo'.

Percebe-se, ainda, que as atividades do serviço, mediante à purificação da consciência que proporcionam, manifestam no praticante o 'gosto', ou estado de consciência, a partir do qual essas mesmas atividades, muitas vezes austeras, do ponto de vista material, sejam experienciadas como fonte de prazer espiritual, tal como podemos observar no trecho de uma entrevista concedida pela devota Vaishnavi Vrnda:

Agora, tenho uma filha pequena e não posso mais estar nas ruas diariamente, mas tive a graça de poder fazer esse serviço por alguns anos, e acredito que todos os devotos deveriam saborear esse néctar, mesmo que por apenas alguns meses. Estar nas ruas diariamente é um presente inigualável. Um dia você vai distribuir 100 livros, e em outro dia você vai distribuir 1 . Um dia você vai distribuir livros para pessoas incríveis, e em outro dia um bêbado vai jogar um copo de pinga em você! Estar nas ruas é uma escola, e lá você vai aprender a tolerância, a humildade, o sacrifício, a austeridade e muito mais... E além disso vai desfrutar de um néctar que... Bem, apenas se você provar poderá saber o gosto! (Devi Dasi, 2019b, p. 1)

$\mathrm{Na}$ passagem acima temos um relato em que as dificuldades sofridas para realização da missão devocional são compreendidas como 'néctar', ou seja, uma vivência que é entendida como sendo de reconexão com aquela que é tida como sendo a natureza eterna da alma, o serviço abnegado a Krishna. O que é aparentemente ruim se torna desafiador e assume caráter positivado, assim identificar o ‘belo' e o ‘bom' em situações adversas torna-se o próprio processo de conexão com o divino. Devido a isso é que sugerimos que as redes de associações nas quais se processam as interações implicadas na prática do serviço devocional podem ser compreendidas como laboratórios, onde se realizam as purificações e transmutações que produzem efeitos externos e internos. Aprender a apreciar o 'néctar' é aprender a apreciar a vida devocional, sendo a prasadam a máxima expressão disso. O 'néctar' da devoção, o aprendizado do 'gosto', é o processo de 
de socialização em uma ontologia ${ }^{10}$, conforme destaca Bhakta Rafael, em uma entrevista concedida a Carta de Sankirtana:

Definitivamente, Curitiba foi a cidade mais "maya" que eu já conheci, e, para mim, o templo, apesar de ser um lugar transcendental, me deixava na mental. As condições do templo, o clima da cidade, a chuva e toda a energia de Kali-yuga das pessoas me forçaram a entender que esse era o fim da estrada. A pergunta estava feita: Voltar para casa ou encontrar um gosto superior? Então, lembrei daquilo que eu ainda não havia saboreado: SANKIRTANA!! Um dia, depois de voltar de Florianópolis, dirigi-me ao meu Siksa Guru, Prabhu Hara Kanta, e implorei para distribuir livros. Ele, surpreso, perguntou: "Na chuva? tem certeza?", e eu disse: "Sim Prabhu!!", com muita convicção que era isso que iria me arrebatar de maya. Naquele primeiro dia, não distribuí nenhum livro, e só consegui distribuir mesmo depois de alguns dias, mas o alívio que senti foi incrível, e foi essa experiência que me manteve no templo até hoje. Graças à misericórdia de meu mestre, hoje posso sair e esquecer toda a ilusão desse mundo material levando a consciência de Krishna para todas as pessoas, forçando minha mente manhosa a se lembrar de Deus a todo instante e, dessa forma, ainda que sem apreciar esse néctar, estou realizando que essa é a verdadeira "Maha-Prasada", a grande misericórdia do senhor". (Devi Dasi, 2019a, pp. 2-4)

A vivência do 'néctar' pode ser compreendida, assim, como o momento em que o devoto deixa de se preocupar consigo, de forma individual, e passa a se reconhecer como parte do todo, o coletivo devocional e sua produção de híbridos entre o mundo espiritual e o material na forma dos subprodutos do serviço devocional, a prasadam e os livros. A experiência ontológica se consolida, portanto, com a formação de uma rede associativa de devotos que se coloca em movimento, no sentido de buscar acessar este lugar. O devir se torna, assim, atingível coletivamente, em práticas rituais.

Podemos refletir, ainda, sobre a maneira com que esta vivência do 'néctar' desperta no praticante uma sensação de felicidade e prazer que ocorrem em oposição àquilo que é tido como maya (ilusório), e culmina em atividades que geram a identificação do 'eu' com a matéria, em relação com os demais devotos. O 'néctar' é, simultaneamente, a felicidade decorrente da realização de atividades em prol da satisfação da pessoa divina - do ato de integrar seus passatempos e deles participar - enquanto maya é um tipo de ação que tem como horizonte a satisfação dos próprios sentidos, o que implica num tipo de ato que implica em

\footnotetext{
${ }^{10}$ A imagem do Ser [implicada no conceito de ontologia] é obviamente um solo perigoso para se pensar sobre as conceituações imaginárias não-ocidentais. E a noção de ontologia não é acionada neste trabalho sem considerarmos os seus riscos. Entretanto, pensamos que a caracterização da ontologia é importante por uma razão única e, digamos, tática. Ela age contra o truque da artificialização, frequentemente praticado contra o pensamento nativo, que torna o seu pensamento um tipo de fantasia, reduzindo-o às dimensões de forma de conhecimento ou representação, do tipo "epistemológica" ou, de "visão de mundo", que acentua a diferença a partir da ótica ocidental e eurocêntrica. (Viveiros de Castro, 2003, p. 18)
} 
reação (karma). Enquanto o primeiro promove uma noção de 'eu' integrada a um todo pragmaticamente manifesto na comunidade - estando aí implicada a ideia de que o eu, enquanto parte, só se satisfaz ao servir o todo maior que integra o segundo faz referência a uma concepção de eu individual independente que se relaciona com o divino.

Isto nos leva à outra reflexão, a dizer, como esta felicidade almejada de se alcançar o 'néctar', no movimento Hare Krishna, compreende as emoções provocadas nas pessoas que se engajam?

\section{O ‘NÉCTAR’ COMO O ‘BEM VIVER' E AS ONTOLOGIAS POLÍTICAS}

Ao afirmarmos que a busca pelo 'néctar' gera engajamento em uma coletividade e que o encontro deste 'néctar' é descrito como um momento de felicidade, à ponto deste engajamento tornar-se permanente e gerar adesão ao movimento, podemos qualificar este processo de vinculação como diretamente ligado às experiências afetivas e emotivas. Didi-Huberman trata da emoção como algo que impulsiona para a ação e, assim, também para o engajamento (2016).

O sentimento de reconhecimento de alguém em torno das práticas rituais, ou devocionais, pode ser compreendido, assim, como um fator de motivação para o próprio engajamento no movimento. $\mathrm{O}$ acesso à ontologia proposta pelos Hare Krishna, seja através dos livros, da alimentação, do contato através dos mantras, não "convence" somente como uma explicação de mundo possível, dentre outras, mas também porque engaja, no sentido que "cria vínculos e associações" entre os participantes e as Deidades. Nós podemos olhar para esses vínculos, assim, a partir da dimensão afetiva, evidenciando os sentimentos e emoções descritas pelos devotos em relação à sua própria prática devocional.

Didi-Huberman afirma que sentimentos aparentemente "espontâneos" podem ser compreendidos como derivados de processos sociais que estabelecem quais emoções são socialmente aceitas nestes momentos (2016). Além disso, as emoções, à medida em que são socialmente organizadas e, portanto, compartilhadas, podem ser importantes aspectos de engajamento, dada a potencialidade que elas têm de aproximar possíveis adeptos. A superação de maya, ou do que é ilusório, é descrito como um sentimento, que é a felicidade encontrada ao se estabelecer a relação com as Deidades e se alcançar o 'néctar'.

A emoção pode ser compreendida, portanto, como algo imprescindível para o engajamento, onde o 'néctar' pode ser descrito como uma categoria nativa utilizada para caracterizar o sentimento experienciado pelos devotos na vida 
ritualizada do movimento Hare Krishna. O reconhecimento de alguém enquanto um devoto Hare Krihna é definido não somente pelo engajamento nas práticas rituais, mais, sobretudo, pelas emoções vinculadas a estas práticas. A satisfação pode ser compreendida como o objetivo que todo devoto busca em suas práticas, e esta pode ser expressa como uma emoção relacionada ao sentimento de desprender-se de si e se aplicar nas atividades que o vinculam com o todo. Este vínculo com o todo, ou com Krishna, é sentido e vivido pelos devotos como um engajamento efetivo com a comunidade de praticantes que forma o coletivo.

A esfera emocional imbricada na prática devocional passa, assim, a se configurar como uma experiência encarnada, como afirma Vidrio (2016), que é compartilhada pelos devotos. A felicidade, neste caso, pode ser compreendida como o 'néctar', quando acessado coletivamente nos rituais Hare Krishna. O sentimento de conexão com as Deidades é, portanto, o fator de engajamento e também o resultado esperado neste processo de participação. A emoção, por fim, é sentida e gera um sentido entre os participantes, ou seja, gera o reconhecimento enquanto devoto que busca e acessa uma relação de proximidade com o divino, vivenciada na pragmaticidade das associações que o integram ao movimento. Constatamos, portanto, que ser Hare Krishna é uma postura ontológica e emocional, que assume o engajamento no coletivo como intrínseco à própria relação com as Deidades e como a condição para se alcançar o 'néctar'.

Buscamos compreender a coletividade, por sua vez, nos debruçando sobre o que a significação atribuída à palavra 'movimento' para os Hare Krishna, uma vez que estes se intitulam de tal forma. Para tal análise, compreendemos esta noção de 'movimento' expressa pelos Hare Krishna, como perpassada por essa relação com a coletividade. Relacionamos, ainda, esta visão ontológica de mundo, que direciona a ação dos adeptos para uma ação coletiva.

Julgamos pertinente, a partir destas relações com conceitos clássicos acerca da temática dos movimentos sociais, retomar ao menos uma definição que embasa a literatura acerca do tema, na Sociologia. Como definição clássica ${ }^{11}$ adotamos a proposta de Touraine, que aborda os movimentos sociais como agrupamentos que reúnem pessoas que se identificam em torno de um projeto e, simultaneamente, em oposição a outro projeto/grupo. Touraine propõe ainda que os movimentos sociais não se enquadram em uma única forma de conflito e de

\footnotetext{
${ }^{11}$ Goss e Prudencio (2004) fazem uma síntese sobre as transformações pelas quais a definição de movimento social passou desde a década de 1970, inclusive na própria formulação de Touraine. Destacamos que a definição aqui adotada pode ser considerada clássica, segundo as autoras, pois é a referência utilizada para as formulações posteriores, em autores como Melucci e Castells.
} 
identificação, e que essas variam, em torno de questões estruturais e/ou culturais, que ele chama de "identitárias" (2003).

A partir da definição proposta por Touraine, podemos adensar nossa análise, ao refletir sobre o movimento Hare Krishna, pois é notório que existe o compartilhamento de uma identificação daqueles que aderem ao trabalho devocional como forma de construção ontológica e emocional. É na coletividade, portanto, que o movimento se concretiza e se realiza. Neste sentimento de realização em relação às práticas devocionais que os adeptos se 'movimentam', no que Didi Huberman (2016) afirma ser a pulsão emocional que embasa as práticas coletivas.

Destacamos, ademais, um aspecto que nos chamou a atenção em relação ao perfil dos devotos durante o trabalho de campo: os participantes do movimento são, majoritariamente, jovens ${ }^{12}$. Apesar de levar seus integrantes a uma interação com o espaço público, o engajamento no movimento Hare Krishna não pressupõe necessariamente um conflito em torno de um objeto social, bem como não define um oponente, ou um grupo opositor. Assim poderíamos dizer que ele não é um movimento social ou um movimento juvenil, nos sentidos definos por Touraine (2003).

Tendo em vista essas carcaterísticas, ele poderia ser melhor designado, a partir do esforço classificatório de Reguillo (2003) no que tange ao estudo da sociologia da juventude, como um coletivo juvenil. Para a autora, esse termo se refere a uma reunião de vários jovens na qual existe uma certa organicidade e cujo sentido prioritário estaria dado por um projeto ou atividade compartilhada (Reguillo, 2003, p. 111). No caso em questão esse eixo aglutinador, tal como argumentamos no tópico anterior, é a adoração ritual às Deidades no templo, mediante a prática do serviço devocional, que tem sua expressão máxima no canto do maha-mantra e na prática de distribuição de livros, denominada sankirtana. As atividades missionárias são vistas como parte integrante desse processo, na medida em que realizam a profecia de Sri Caitanya, ao propagarem o maha mantra por todas as vilas e aldeias (Carvalho, 2018, p. 80).

A conformação do movimento Hare Krishna, nos remete, portanto, a esta definição de coletivo juvenil, não porque se limita à questão etária observada, mas principalmente, pelo traço existencial que, como coloca Ana Luisa Sallas (2009), seria uma das marcas da experiência vivencial da juventude tal como foi construída no Ocidente. Segundo a autora, se por um lado, os jovens vivem intensamente um processo de busca por individualização e incerteza diante do

12 Adotamos aqui a definição do Estatuto da Juventude como referência, em que jovens são os cidadãos da faixa etária de 15 a 29 anos $\left(\right.$ Lei $\left.N^{o} 12.852,2013\right)$. 
futuro - algo que, como aborda a autora, seria talvez próprio da juventude - existiria também nesse momento de vida: "a criação de relações que promovem certamente sentidos de pertença em grupos, em redes de solidariedade e de confiança que assinalam para um vir a ser de esperança diante de tantas incertezas" (Sallas, 2009). Essa procura por autonomia e diferenciação, concomitante à busca por cooperação e integração seriam, segundo Sallas, faces de um mesmo processo que tem marcado a vida dos jovens nas modernas sociedades industriais.

Partindo dessa reflexão, que toma a fase da juventude como um momento de abertura para outras possibilidades de vir a ser e gera engajamento em grupos, acreditamos que essa identificação gera, consequentemente, uma diferenciação com os 'outros'. Tal diferenciação, por sua vez, não caracteriza o conflito descrito por Touraine (2003) como essencial para a conformação de movimentos sociais, mas cria uma oposição ontológica em relação aos que não são adeptos do movimento. Isso porque a prática devocional cria a identidade e esse sentimento de pertencimento ao grupo. A oposição se dá, portanto, aos que vivem e aspiram outras ontologias, não ancoradas na vivência comunitária e na busca e realização do 'néctar'. O movimento pode ser caracterizado, assim, como engajado na construção desse 'néctar', ou 'bem viver', como já tratamos, em que jovens agem, coletivamente. Faz-se necessário, portanto, caracterizarmos o que consideramos aqui o cerne deste projeto ontológico, que acreditamos ser político.

Buscaremos demonstrar porque afirmamos que existe uma dimensão política implícito ao envolvimento no movimento Hare Krishna. Para isso, buscamos uma ampliação desse conceito para além das ações institucionais geralmente entendidas enquanto tal. Como comentado na introdução, a concepção de política que aqui nos serve de horizonte para essa sugestão partilha de um pressuposto segundo o qual a ontologia, a realidade produzida pelas práticas devocionais, é múltipla, havendo várias versões possíveis da realidade. Tais questões, como coloca Souza (2015), têm a ver com o que Mol (1999) chamou de política ontológica. Ou seja, têm a ver com o modo em que o real está implicado no político e vice-versa. Assim,

se o termo 'ontologia' é combinado com 'política', isso sugere que as condições de possibilidade não estão dadas. Que a realidade não precede as práticas mundanas por meio das quais nós interagimos com ela; mas é, ao invés disso, modelada no interior destas práticas. Então, o termo política serve para sublinhar esse modo ativo, este processo de modelagem e o fato de que seu caráter é tanto aberto quanto contestado. (Mol, 1999: 75 , tradução nossa). 
A partir de tal citação podemos afirmar que, para Mol (1999) a realidade nunca foi considerada algo totalmente imutável. No entanto, a tecnologia e a política institucionais, por exemplo, em suas operações convencionais, tem como um pressuposto a ideia de que o mundo pode ser controlado, dominado, modificado. Para isso tais ações tomam a realidade como uma entidade permanente e exterior, passível de ser revelada por meio das minúcias da investigação científica. Como uma reação crítica a esse posicionamento, nas últimas décadas, como aponta Souza (2015) as divisões padronizadas de presente e futuro, "entre o que está consolidado e o que ainda está em processo de formação, entre os tijolos que constituem a realidade e os modos de ajustá-los, passaram a ser duramente criticadas" (Souza, 2015, p. 6). Os elementos que compõem a realidade, nessa perspectiva, não são dados a priori, nem são estáveis ou universais; ao contrário disso, eles são histórica, cultural e materialmente localizados, algo que, segundo Mol (1999), adiciona a esse fenômeno o caráter da multiplicidade e do potencial de transformação.

Essas ideias têm uma repercussão profunda na maneira como se concebe, não somente a realidade, mas também os próprios métodos de conhecimento científico, que deixam de ser vistos como mecanismos para acessar o real, e passam a ser compreendidos como o que "possui efeitos, produz diferença, constrói realidades e ajuda a criar aquilo que descobre" (Law; Urry, 2003). O movimento Hare Krishna propõe uma ontologia que perpassa a ação coletiva voltada para a transformação social. Para compreender esse fenômeno como político faz-se necessário, portanto, aderir à perspectiva teórica de que o real é passível de transformação e de que existem, atualmente, práticas múltiplas e diversas de projeção e, ao mesmo tempo, construção destas ontologias.

Para lidar com o fenômeno da multiplicidade de ontologias, ou de ontologia políticas, faz-se então necessário que, ao invés de nossas reflexões priorizarem a análise partindo de diferentes perspectivas abstratas, que sejam feitas seguindo os objetos nas próprias práticas que os fazem existir. A questão então deixa de ser sobre os modos pelos quais as diferentes ciências representam a realidade, para se tornar uma reflexão sobre os caminhos práticos mediante os quais os diferentes conhecimentos nela intervêm. 


\section{CONCLUSÕES PRELIMINARES}

Através desse breve percurso reflexivo experimentamos uma tentativa de situar o movimento Hare Krishna como político, concebendo a política de forma mais ampla do que aquela que a restringe ao limite das instituições convencionalmente definidas como tal. Nos ancoramos na noção de política de Mol (1999) à medida em que consideremos a prática e pensamento de outros mundos como um ato político, através do engajamento de pessoas na implementação e vivência de sua noção de 'bem viver'.

Esse processo, mediante o qual uma existência coletiva juvenil crítica adquire corporeidade, através das práticas cotidianas dos atores, nos remete à proposição de Reguillo (2000), de que a política não é um sistema rígido de normas, mas uma rede variável de práticas, uma bricolagem de formas e estilos de vida estreitamente vinculados a produção coletiva de um modo outro de viver (Regui1lo, 2000, p. 43).

Nesse escopo é que identificamos as práticas coletivas nas quais os membros do movimento Hare Krishna se engajam e, ancoradas nelas, buscam seu ideal de 'bem viver', que se exprime em um termo de uso comum na interação em torno das diferentes práticas: o 'néctar'. Acreditamos que estas podem ser compreendidas como políticas, portanto, pois se trata de uma experiência que os unifica enquanto um coletivo e os movimenta, no sentido de organizar práticas que produzam os mundos particulares em que suas noções de pessoa são reelaboradas. Mais do que a relação com os não adeptos, esta experiência está pautada na vivência dos devotos em suas práticas, que são impulsionadas pela busca do sentimento de felicidade partilhada, alcançado nos rituais devocionais.

O devir que anunciam é, assim, um sentido de coletividade enunciado enquanto um sentimento vivenciado no real. Existe, portanto, uma ontologia que organiza e orienta a ação dos Hare Krishna. Ela pode ser compreendida como política, desde que a noção de política considere que o sentido coletivo atribuído à produção das práticas coloca em ação o jogo cósmico, ou lila, pela qual a presença de Sri Caitanya se torna palpável aos seus devotos.

A distribuição de livros e alimentos e suas redes heterogêneas de associações, podem ser compreendidas, assim, como os momentos de vivência e transmissão desta ontologia, em que a ritualização acontece como uma forma de ensino e aprendizagem por parte dos devotos. A experiência deixa de ser individual e passa a ser compartilhada à medida em que é percebida pelos praticantes dos 
rituais como geradora de sentido. A devoção é, portanto, vivida pelos devotos e transmitida por eles enquanto experiência coletiva.

Para os Hare Krishna, os próprios sons, livros e alimentos que distribuem nas ruas são imbuídos de uma agência particular, a qual aponta para um devir específico. Por terem sido associados a Krishna, se considera que eles se tornem tão bons ou potentes quanto o próprio Krishna. Mesmo que a pessoa não compreenda a filosofia ou não chegue a ir ao templo, apenas por saborear uma samosa, por sorrir quando se encontra com uma procissão nas ruas ou ainda apenas por tocar e ver uma das capas dos livros ofertados se considera que pessoa já tenha se beneficiado espiritualmente, obtendo um tipo de saldo piedoso que, quando acumulado, fará com que a pessoa possa desabrochar seu amor latente por Deus ao conviver com seus devotos.

A partir da consideração da agência de objetos presente neste debate, consideramos ainda que podem ser úteis, nessa reflexão final, algumas das ideias elaboradas por Goldman em seu trabalho sobre o fetichismo e o candomblé (2009). Para realizar sua proposta Goldman se utiliza do conceito de devir, o qual seria usado com intuito de prescindir-se da história para que se possa focar diretamente e especificamente na relação, gerando então um tipo de abordagem em que se torna possível definir a religião como "um 'complexo' que contém inúmeras possibilidades ou virtualidades que se atualizarão com maior ou menor força segundo as situações" (Goldman, 2009, p. 110).

O devir então se apresenta como um dispositivo analítico para se referir a uma potência de ação, ou relação, que já está dada virtualmente, mas que depende de determinadas associações ou relações para que possa vir a manifestar aquilo que, de fato, já é. No caso do movimento aqui em questão, essa potência ou relação dada virtualmente seria o próprio intercâmbio amoroso entre as almas e Deus (Krishna), manifesto praticamente na forma do serviço, pois todas as entidades vivas são devotas em potencial por serem partes fragmentárias do todo. O contato com os objetos e elementos ativados pela associação com a Deidade são vistos, assim, como as relações que tem a potência de manifestar essa condição natural latente a todas as almas.

É neste sentido que o devir implica na busca pela produção de um 'bem viver'. Nos momentos em que os devotos "provam deste néctar", ou seja, acessam este estado de diluição de si mesmo e de integração com o todo, pode ser compreendido como um momento disruptivo, em que a noção de um mundo espiritual se torna, também, palpável e sentido como real. 
Os elementos evidenciados ao longo deste texto sugerem que o caráter político do movimento Hare Krishna se manifesta quando passamos a compreender o modo pelo qual as atividades culturais, que ocorrem no âmbito comunitário e missionário dessa rede, se encontram fundamentadas na noção de 'bem viver', que acaba por criar condições para que as pessoas se envolvam de maneira intensa e engajada.

Poderíamos ainda nos questionar o porquê ampliar o entendimento da política? Vivemos um tempo de trincheiras, em que a verdade anda em disputa. Imaginando a metáfora dos fenômenos históricos como ciclos, podemos pensar os tempos atuais - de desesperança e desilusão na esfera política, com a temporária derrota do campo progressista consolidada com o golpe político de 2016 (Jinkings et al., 2016). Faz-se por vezes imperativo reinventar devires, perspectivas de futuro e de alegria - uma das mais radicais formas de política - para suportar a enfrentar a própria realidade escancarando sua natureza transitória.

\section{REFERÊNCIAS}

Acosta, A. (2016). O bem viver: Uma oportunidade para imaginar outros mundos. Autonomia Literária; Elefante. https://doi.org/10.7476/9788578794880.0006

Carvalho, L. A. G. (2018) Hare Krishna: das origens à chegada e expansão no Brasil. Terceira Via.

Devi Dasi, V. V. (ed.). (2019a). Carta de Sankirtana, (120). http://cartadesankirtana.com.br/wpcontent/uploads/2019/06/Maio.pdf

Devi Dasi, V. V. (ed.). (2019b). Carta de Sankirtana, (124). http://cartadesankirtana.com.br/wpcontent/uploads/2019/10/Setembro.pdf

Devi Dasi, V. V. (ed.). (2019c). Carta de Sankirtana, (125). http://cartadesankirtana.com.br/wpcontent/uploads/2019/11/Outubro.pdf

Didi-Huberman, G. (2016). Que emoção! Que emoção? Editora 24.

Duarte, R. (1998). Bhagavad Gita: Canção do Divino Mestre. Companhia das Letras.

Favret-Saada, J. (1977). Les mots, la mort, les sorts: La sorcellerie dans le bocage. Gallimard.

Garfinkel, H. (2006). Studios en etnometodología. Anthropos.

Goss, K. P., \& Prudencio, K. (2004). O conceito de movimentos sociais revisitado. Revista EmTese, 2(1), 75-91.

Goldman, M. (2009) Histórias, devires e fetiches das religiões afro-brasileiras: ensaio de simetrização antropológica. Análise Social, 44(190), 105-137.

Gordon, C. (2014). Bem viver e propriedade: o problema da diferenciação entre os XikrinMebêngôkre (Kayapó). Mana, 20(1), 95-124. https://doi.org/10.1590/S010493132014000100004 
IBGE (2020). Panorama de Curitiba. https://cidades.ibge.gov.br/brasil/pr/curitiba/panorama

Jinkings, I., Doria, I., \& Cleto, M. (eds.). (2016). Por que gritamos golpe? Para entender o impeachment e a crise política no Brasil. Boitempo.

Lei $N^{o}$ 12.852, de 5 de agosto de 2013. Institui o Estatuto da Juventude e dispõe sobre os direitos dos jovens, os princípios e diretrizes das políticas públicas de juventude e o Sistema Nacional de Juventude - SINAJUVE. Brasil. Presidência da República. Casa Civil.

Mol, A. (1999) Ontological Politics. A Word and Some Questions. In J. Law \& J. Hassard (ed.), Actor network theory and after (pp. 74-89). Blackwell Publishing. https://doi.org/10.1111/j.1467-954X.1999.tb03483.x

Prabhupada, A. C. B. S. (1979). Life comes from life. Bhaktivedanta Book Trust.

Reguillo, R. (2000) Culturas juveniles: Formas políticas del desencanto. Ayres Veintiuno.

Reguillo, R. (2003). Las culturas juveniles: um campo de estudio. Breve agenda para la discusión. Revista Brasileira de Educação, (23), 103-117. https://doi.org/10.1590/S1413-24782003000200008

Sallas, A. L. F. (2009). Cultura e sociabilidade na constituição dos imaginários juvenis latinoamericanos. In XXVII Congreso de la Asociación Latinoamericana de Sociología. https://cdsa.aacademica.org/000-062/1810

Sallas, A. L. F., Duarte Villa, R., Silva Bêga, M. T., Bôde de Moraes, P. R., Amaral, C., Coelho de Andrade, C., Coelho Silva, S. L., Bittencourte Guimarães, P. R., \& Waiselfisz, J. J. (1999). Os jovens de Curitiba: Esperanças e desencantos. Juventude, violência e cidadania. UNESCO.

Segato, R. (1992). Um Paradoxo do Relativismo: o discurso racional da Antropologia frente ao Sagrado. Religião e Sociedade, 16(1-2), 114-135.

Souza, I. M. de A. (2015). A Noção de Ontologias Múltiplas e suas Consequências Políticas. ILHA 17(2), 49-73. https://doi.org/10.5007/2175-8034.2015v17n2p49

Swami, D. (2019). Em busca da Índia Védica. Bhaktivedanta Book Trust.

Tambiah, S. J. (2018). Uma abordagem performativa do ritual. In S. J. Tambiah (ed.), Cultura, pensamento e ação social: Uma perspectiva antropológica (pp.134-182). Vozes.

Teles, J. E. (2016). Cosmologia e alteridade: nota etnográfica sobre os interstícios de uma específica situação de campo. Revista Nures, (32). https://revistas.pucsp.br/index.php/nures/article/view/28749

Theodor, I. (2015). Contexto e Estrutura da Bhagavad-Gita. In R. Sousa Silvestre \& I. Theodor (eds.), Filosofia e Teologia da Bhagavad-Gita: Hinduísmo e Vaishnavismo de Caitanya (pp. 27-65). Juruá.

Tilly, C. (2006) Regimes and repertoires. University of Chicago Press. https://doi.org/10.7208/chicago/9780226803531.001.0001

Touraine, A. (2003). Poderemos viver juntos? Iguais e diferentes. Vozes.

Valera, L. (2015) A mística devocional como experiência estética: Um estudo do Bhaktirasamrta Sindhu (Tese de doutorado, Universidade Federal de Juiz de Fora). Repositório Institucional - UFJF. http://repositorio.ufjf.br:8080/jspui/bitstream/ufjf/178/1/luciovalera.pdf 
Velho, O. (1998) O que a Religião pode fazer pelas Ciências Sociais? Religião e Sociedade, 19(1), 9-17.

Vidrio, S. (2016) El papel de las emociones en la conformación y consolidación de las redes y movimientos sociales. In: M. Ariza (ed), Emociones, afectos y Sociología Diálogos desde la investigacion social y la interdisciplinar (pp. 399-440). UNAM.

Viveiros de Castro, E. (2003). Manchester papers in Social Anthropology. http://abaete.wikia.com/wiki/(anthropology)_AND_(sci-

ence)_(E._Viveiros_de_Castro). 